\title{
El tsombiach: tejiendo la vida entre memoria y tradición ${ }^{1}$
}

\author{
Silvia Daniela Leyva Mosquera ${ }^{2}$ \\ Pontificia Universidad Javeriana, Bogotá, Colombia ${ }^{3}$ \\ trasegantedeespigas@yahoo.com
}

Recibido: 22 de enero de 2014

Aceptado: 29 de abril de 2015

Disponible en linea: 30 de noviembre de 2015

\footnotetext{
1 Este artículo es el resultado de un proyecto de investigación de la facultad de Ciencias Sociales de la Pontificia Universidad Javeriana de Bogotá, Colombia. Fue financiado por la Vicerrectoría de Investigación con el código 5897, con la beca de joven investigadora, habilitada dentro del grupo de investigación del Departamento de Antropología "Identidades y prácticas de poder". Su modalidad es la de un artículo de reflexión, en el que se presentan los resultados de una investigación analítica sobre los procesos textuales y narrativos dentro de la urdimbre de las fajas tsombiach que tejen las mujeres kamëntsá del alto Putumayo. Deseo aquí agradecer a las batás María Georgina Juagibioy, Margarita Chindoy, Pastora Juagibioy, Dolores Butumbajoy, María Luisa Jasansoy por la ayuda y cariño con el que me permitieron llevar a cabo este proceso. De igual forma, quiero agradecer la paciente guía del profesor Carlos Luis del Cairo Silva, tutor de este proyecto y director del Departamento de Antropología.

2 Profesional en Estudios Literarios.

3 Joven Investigadora, grupo de investigación del Departamento de Antropología "Identidades y prácticas de poder", y del Instituto de Estudios Sociales y Culturales PENSAR.
} 


\title{
El tsombiach: tejiendo la vida entre memoria y tradición
}

\section{Resumen}

El tsombiach o faja de lana tradicional de las mujeres indígenas kamëntsá del alto Putumayo presenta, simbólica y sintéticamente, la historia tradicional de la comunidad y la experiencia personal de sus artífices y portadoras, quienes narran con una estética particular la manera como el tejido anima la vida comunitaria. En el artículo se da cuenta de la interrelación e integración de este tipo de expresión textual y oral con la literatura. Las claves metodológicas parten de la experiencia etnográfica de la autora y de un abordaje teórico desde nociones de la antropología simbólica y de la perspectiva alternativa de las literaturas heterogéneas. Palabras claves: tsombiach; kamëntsá; tejido; literaturas indígenas; tejedora; memoria

\section{The tsombiach: weaving life between memory and tradition}

\begin{abstract}
The tsombiach or traditional wool sash of the Kamentsa indigenous women from the high Putumayo presents symbolically and synthetically, the traditional history of the community and their creators and carriers' personal experiences, who narrate with a particular aesthetic how the weave lifts community life.The article accounts for the interrelationship and integration of this type of textual and oral expression with literature. The methodological keys are based on the the author's ethnographic experience and a theoretical approach from notions of symbolic anthropology and the alternative perspective of heterogeneous literatures.
\end{abstract}

Keywords: tsombiach; Kamentsa; weave; Indigenous literatures; weaver; memory

\section{O tsombiach: tecendo a vida entre memória e tradição}

\section{Resumo}

O tsombiach ou faixa de lã tradicional das mulheres indígenas kamëntsá do alto Putumayo apresenta, simbólica e sinteticamente, a história tradicional da comunidade e a experiência pessoal das suas artífices e portadoras, quem narram com uma estética particular a maneira como o tecido anima a vida comunitária. No artigo dá-se conta da inter-relação e integração desse tipo de expressão textual e oral com a literatura. As chaves metodológicas partem da experiência etnográfica da autora e de uma abordagem teórica desde noções da antropologia simbólica e da perspectiva alternativa das literaturas heterogéneas.

Palavras-chave: tsombiach; kamëntsá; tecido; literaturas indigenas; tecedora; memória 


\section{Introducción}

Entre las mujeres indigenas kamëntsá del suroccidente colombiano, la urdimbre de la faja cinturón o tsombiach representa un vehículo flexible de transmisión de historias. Este es un objeto textil con connotación eminentemente femenina, cuya materialidad representa el entorno comunitario. Por ejemplo, la lana y los tintes vegetales con los que la tiñen cobran un significado especial: las mujeres dicen que una vez se tiza la lana virgen, esta se asemeja a un bebé al que, con los debidos cuidados, se le impregnan diversas concepciones culturales de la naturaleza. Así, el huso y el devaneo de la lana son procesos que implican la humanización de las fibras. En esos procesos se hace evidente la tensión entre la representación simbólica del textil y su función práctica, asociada a la protección del vientre, especialmente durante el embarazo.

En este contexto, el propósito de este artículo es examinar el componente simbólico y narrativo del tsombiach a partir de su connotación como matriz de relatos y condensación de nociones e ideas entorno a los valores semánticos y culturales de la comunidad kamëntsá. El análisis se fundamenta en la experiencia etnográfica de la autora con varias tejedoras kamëntsá, a partir de la acción del tejer y de la interpretación que de él da cuenta cada una de las artesanas. De igual forma, las claves de lectura derivan de aproximaciones antropológicas que destacan cómo la vida humana, animal y vegetal se entrelazan en un mutuo y constante cauce de relaciones reciprocas (Aguilera, 2014). Se hará uso de un enfoque simbólico (Reynoso, 1987) para explorar la carga semántica y expresiva que nutre las representaciones metafóricas del tejido y sus límites entre lo oral y lo escrito, en tanto que formas de expresión híbridas y complementarias

El tsombiach tiene características análogas a la condición dual y a la vez articulada del territorio tradicional de los kamëntsá: el piedemonte andino y la selva. La montaña y la selva que confluyen en el piedemonte del valle del Sibundoy fueron descritas por Wade Davis como un "derrotero común de ideas y bienes compartidos a través del corazón del continente" (2001, p. 163). Gracias a su condición de bisagra se 
posibilitan en esta región las "manifestaciones de tradiciones andinas y selváticas como resultado de su situación de frontera entre Andes y selva" (Ramírez, 1996, p. 27), lo que implica una dinámica donde diversas cosmovisiones coinciden al considerarse herederas del complejo cultural del yagé.

Así como el piedemonte actúa como bisagra, la faja precisa de una cualidad sintética que asume una posición abierta al diálogo, en el que encuentra su expresividad con el entorno que es tanto ancestral como contingente. Esta característica de la contingencia la que formalizará la intención del artículo, el cual intenta explicar cómo se funden las tradiciones orales y la escritura de carácter alternativo dentro del tsombiach. Para tal fin, el atexto se compone de tres partes: la primera resalta la materialidad de la faja con el sistema de creencias kamëntsá, el cual se basa en una cosmovisión nutrida por el entorno ambiental y sus repercusiones en la creación de sentidos y significados. La segunda analiza la textualidad alternativa que representa el tsombiach y cómo esta desafia los límites convencionales entre oral y lo escrito. Finalmente, en la última sección se aborda la experiencia personal de las tejedoras como una historia de transformación en torno al tejido, en el cual se retroalimentan los relatos urdidos con los vividos por las batás ${ }^{4}$. En sintesis, el artículo intenta visibilizar estas creaciones como parte de un tipo de literaturas heterogéneas, cuyo referente principal se basa en lo oral y en una escritura no alfabética.

\section{La faja}

De la vasta producción textil del mundo kamëntsá, el tsombiach o faja cinturón de lana se comporta como una matriz de historias en la que se inscriben, de forma gráfica y colorida, las labores o diseños simbólicos que son asociados al mundo femenino. En esta faja se esbozan elementos de integración colectiva como el yagé en su olla y la chagra (jajañe) o huerta tradicional kamëntsá, considerada como la despensa de la vida.

4 Término kamëntsá para tías y por extensión, sabias. 


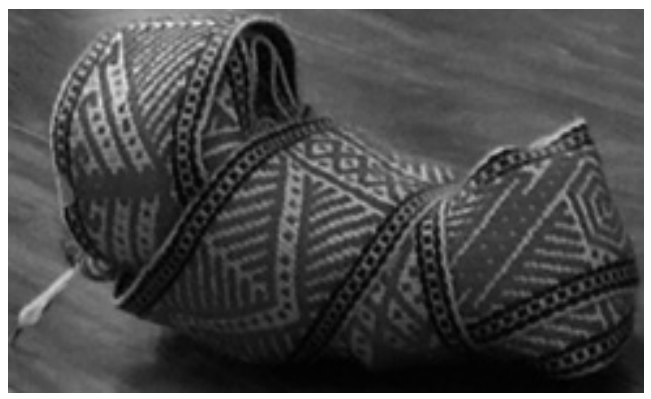

Figura 1. Tsombiach envuelto de manera tradicional.

Fuente: fotografia de un tsombiach urdido por doña Margarita Chindoy realizada por la autora.

Las labores, en su mayoría romboidales, funcionan como pictogramas o signos que representan de forma más o menos esquemática un símbolo o también como ideogramas (convenciones de imágenes que operan a partir de una relación abstracta de ideas). La lectura de las fajas implica conceptos precisos sobre lo cotidiano y lo folclórico. Es así como la figura del maíz, del oso y del monte son diseños relacionados con la acción de tejer. Por consiguiente, el tsombiach es parcialmente autoreferencial; su tejido tiene entre sus temas el tejido mismo. Por esta característica es posible observar cómo se cifra la experiencia de vida de las batás en la práctica de tejer y en la manera personal en la que a cada una se le revela un camino de conocimiento por medio de historias específicas, a las cuales se les da la connotación de 'físicas' y, por tanto, de ejemplares y verdaderas. La batá Margarita Chindoy, al referirse a relatos, nos indica que estos reúnen las nociones de lo intimo, de la conservación de la tradición y unidad generacional:

No es por historia sino que las cosas son muy verdaderas, si es por eso, historias hay hartísimas. Para tejer una mejor historia y tener claro viendo lo personal fisicamente. Yo quisiera contarles, porque físicamente eso se llama historia, para los niños de este tiempo eso sí es antiguo. [...] Entonces, sí, para nosotros nos queda como historia antigua, que tenga de sabor. Que digan que ellos nos contaban lo que había pasado o lo que había mirado, o conoció, o miró. (Comunicación personal, mayo 23, 2014) 
Dolores Butumbajoy, madrina de doña Margarita, en Mocoa, esclarece que las historias se hacen comprensibles en la medida en que siembren una relación de reciprocidad y respeto por la trascendencia del otro. El aprendizaje adquirido en la escucha no solo significa la adquisición de ciertos códigos culturales, sino un acto de profunda reverencia a quien ya ha vivido, puesto que su palabra no solo es experiencia y precepto, sino también una estética de la sabiduría (Chacón, 2007, p.99).

La batá doña Pastora Juagibioy expresa que la finalidad del tsombiach y de las historias que se inscriben en él es la reflexión además de, la limpieza personal, pues en la huerta y en el tejido:

[...] uno deja de lado aquello que no sirve, que de crecer, podría dañar el jardín, la vida, la urdimbre. La vida misma está cortada como la faja, uno sabe cuándo terminar de hilar la historia, así como Dios sabe cuándo finalizar la visión y la palabra. (Diario de campo, marzo 21, 2014)

Las figuras de la faja cobran sentido desde la vivencia que cada batá tiene con los diseños y con su lectura tradicional. Por ejemplo, la labor del maíz se interpreta en general como la recolección que da prosperidad a la familia y, de forma individual, como se verá más adelante, su significado trasciende la convención para interiorizarse como un correlato no solo comunal, sino también particular, nutrido de la experiencia propia. Las labores que se urden en la faja poseen una forma de lectura que no se asocia a la forma sistemática y secuencial de los textos alfabéticos, ya que su carácter radica en una comprensión del espacio y del sentido de la escritura como un hecho que abarca más valores que aquellos enmarcados como puros signos lingüísticos $\mathrm{y}$, a la larga, fraccionados y segmentados por un orden imputado del sentido o de la razón que resultan de la fonética ${ }^{5}$, como intercambio de significados convencionales.

Siguiendo a Philippe Sollers, en su muy esclarecedora contribución sobre la reflexión de la escritura a propósito de De la Gramatología de Jacques Derrida, podemos argumentar que "la escritura fonética alfabética hace de la representación una función filtrada por el habla (la escritura se convierte en un sistema de significantes cuyos significantes son los fonemas [...] la escritura alfabética indica una etapa específica de la constitución de la moneda como circulación de signos arbitrarios" (Sollers en Derrida, 2010, p.IX). 
Para las batás, esta urdimbre corresponde a una manifestación plena del lenguaje, de la escritura/tejido como un reverso, un desplazamiento de los caracteres fijos que vislumbra una serie de elipsis, de nudos que significan determinaciones simbólicas en tanto que prácticas en su hacer discursivo, pues las labores o el tejido en general, al igual que las palabras, se hacen y se deshacen, lo que da cuenta de la comunión y el olvido, pautas de entrecruzamiento que obedecen más a la memoria, entendida no solo como palabra o huella sino como imagen, como una suerte de hibridación en la cual prevalece la necesidad de perdurar en la experiencia como mnemotecnia y, a la vez, como poder creativo ${ }^{6}$. En relación con lo anterior, Carlo Severi (2012) argumenta que:

Further empirical research will doubtless shed light on this question. In the meantime, however, it is as well to consider the following broad theoretical point: the opposition between mnemonic devices and writing is, in fact, extremely fragile from a conceptual point of view, all of these diverse techniques must necessarily fall into one of two camps. Either a society relies on oral memory, giving rise to loose, fragile traditions, or it develops techniques for transcribing language, leading ultimately to writing. Many Amerindian cultures, however, fall outside this crude opposition: the practice of social memory and the use of organized iconographies go together in these traditions, which developed arts of memory that cannot be reduced to either writing or to individual mnemonic devices.

A propósito de lo anterior, el filósofo francés Jacques Derrida recuerda que hay que darle cabida a una escritura que abarque todo tipo de experiencia humana, puesto que "la satelización de la escritura ha

6 A lo anterior se suma la precisión sobre la manera en la que la que el paradigma occidental siempre busca la violencia de los opuestos, para fortalecer las diferencias que subyacen a cosmovisiones que operan de acuerdo con pautas epistémicas variadas, y no por eso privilegiadas por su diferencia sino por su carácter plural: "Historians of the arts of memory, for their part, will need to make space within their findings for new perspectives drawn from outside the Western world. This new approach implies a combined comparative and reflexive research strategy. If the idea of the art of memory is to be applied to non-Western traditions, then it is not enough merely to show that some of its concepts can be fruitfully applied to their memorization techniques. We must also bring what Lévi-Strauss called "the view from afar" to bear on the Western case. Seen from this perspective, both classical and medieval arts of memory can be classified as belonging to one ideal type from a whole series of thought techniques that can give rise to a tradition" (Severi, 2012, p. 545). 
creído constituirse para en siempre en el interior de la escritura, en un adentro ficticio, equivalente a la propia capacidad de representación de un sujeto" (Derrida, 2010, p. 9). Por esta razón, la lectura no-alfabética del tsombiach constituye un resquebrajamiento en las nociones que privilegian las expresiones familiares de la escritura, la palabra e, incluso, la misma lectura, que es vertical y que se efectúa a la manera en la que se teje, como perpetuando, hilando y deshaciendo la extensión del tsombiach, como altura de un ser que nace siendo ovillo, crece y se alarga para luego ser como serpiente que se enrosca, cargada de vida y color en torno al vientre.

El significado de la faja depende entonces del acercamiento y conocimientos tradicionales que cada artesana o portadora tenga sobre el tejido. Una lectura de los signos de la faja según valores fonéticos resulta inútil, pues las inscripciones no son signos con valor fonético establecido, sino que son más bien convenciones que reúnen un potencial de evocación y que ahondan en una comprensión simbólica y narrativa, es decir, en un valor expresivo. Reynoso aclara cómo la estrategia expresiva puede interpretarse como una acción reciproca de escenas, actos y agentes que resaltan el poder del lenguaje figurativo, donde la metáfora es capaz de organizar las escenas de la vida y sus representaciones $(1987$, p. 42).

Además de la narración significativa y personal que posee el tsombiach, las mayoras lo atesoran por su capacidad -como cuenta doña Pastora Juagibioy- de "proteger el vientre y la vida, pues de ahí parte no solo la descendencia sino la tradición" (Comunicación personal, marzo 21, 2014). La extensa longitud de la faja que da hasta cinco y siete vueltas en torno al abdomen bajo de las mujeres, envuelve su cuerpo en el sentido de las agujas del reloj. Adicionalmente, concebida para urdirse con lana de oveja virgen, la faja goza de cualidades medicinales y espirituales especiales. En la esfera de la salud, la lana es muy apetecida por la cera grasosa producida por el ganado bovino, o lanolina, de la cual se adquieren grandes beneficios. La batá María Luisa Jasansoy relata que 
[...] la lana de las ovejitas es milagrosa, sirve para dar calor, pero además se puede usar para dormir bien y espantar a los malos espíritus. La lana une con los ancestros, con ella se pueden hacer desde aceites para el dolor de oído, hasta pomadas para los bebés y ungüentos para los fuegos de la boca. (Comunicación personal, junio 6, 2014)

Más allá de las propiedades medicinales descritas, la búsqueda de la lana une a la artesana con Tsbatsam Mamá, la madre tierra. Por eso, para manipular este elemento tan preciado se espera la luna ${ }^{7}$ precisa para trasquilar al animal, lo cual es posible hacer desde más o menos cuatro o cinco días de luna creciente hasta la luna llena, para que así el animal no se descarapele y vuelva a tener lana pronto, como cuenta la batá Georgina Juagibioy. Después de seleccionar y trasquilar a la oveja, se tiza, es decir, se limpia la lana. Una vez extraidas motas, pelos y durezas, se prosigue a abrir la lana para lavarla con agua y jabón de tierra. La lana húmeda se deja secando a la luz de Shinye, el sol, y el manojo resultante se amarra con guascas. En este estado, la lana es considerada como un bebé; se le puede alimentar de conocimientos y formar, hasta descubrir en ella su esencia humana. Al separar el material que se va a hilar, se eligen o descartan características que se desean imprimir a la faja, como si se quisieran escoger rasgos para un niño: "que tenga las fibras más gruesas, que sea suave y brillante, que tenga y otorgue concentración" (Diario de campo, junio 24, 2014).

Para separar las fibras se utiliza un palo vertical y delgado de madera de árbol que atraviesa la lana desde su centro u ombligo. El palo atravesado con el manojo se entierra y se separan los hilos, para buscar el cordón umbilical de ese ser que es "pensamiento convertido en hebra" (Muchavisoy, 2003, p. 55). En el huso o retorcedor, la fibra adquiere forma gracias a los movimientos de la batá. La mano izquierda dimensiona el grosor de la hebra con un pequeño movimiento. Los dedos empujan para desenrollar y la mano derecha gira la lana en el

La luna o Juashkon es como una segunda madre que regula los ciclos espirituales y materiales del pueblo, en particular en los procesos germinales y de salud física y psicológica (Muchavisoy, 2003, p. 27). Además, "la tierra y la luna son hermanas gemelas, por eso se ayudan en las cosechas, en la luna le enseñan a uno a sembrar, a cortar las plantas, a hacerse amigo de ellas a saber cuándo es conveniente sembrarlas, cortarlas, limpiarlas, todo lo que hay que hacer con ellas" (Pinzón y Garay, 1998, p. 250). 
huso abriendo una onda, una espiral redondeada que se envuelve de arriba a abajo y de abajo a arriba, como remendando el ciclo de los astros. Este procedimiento refina el devaneo y, a la vez, más adelante extenderá en el tejido la comunicación como una reunión de saberes. Como consecuencia, el retorcedor permite que el hilo complemente su función simbólica según la imagen y dimensión del pensamiento mítico. El volante hace las veces de la tierra; arraiga a la fibra. Por esto, la acción de retorcer impregna una comprensión de los sentidos duales del cosmos, es decir, lo que está arriba y lo que está abajo son valores cuya relación se basan en la complementariedad.

De forma similar, el uso del color implica una dualidad complementaria. Osvaldo Granda Paz afirma que "el color se asume como claridad y se plantea monocromáticamente como ausencia, oscuridad" (2007, p. 70). Para la familia kamëntsá, los colores implican ciclos de iniciación. Por ejemplo, doña Pastora comentaba que el azul oscuro en las fajas representaba la tonalidad del firmamento y que pertenecía a los difuntos; los moribundos pedían que no se les apartara de collares o fajas azules, pues con estos se aseguraban de soportar el juicio de sus almas y podrían gozar de la mansión celestial. Por el contrario, se prohibía durante los estados agónicos portar fajas rojas o con colores vivos, pues, aunque el rojo era el fuego de la vida, se convertía en el rojo del infierno cuando alguien moría (Diario de campo, junio 19, 2014).

Este lenguaje de los colores implica la transitoriedad de la vida y el maridaje con las formas vegetales que enmarcan las diferentes situaciones sociales que asume cotidianamente una mujer u hombre kamëntsá. Parte de esta noción se basa en el hecho de que el color se obtiene gracias al empleo de vegetales y frutas que poseen referentes no solo de función, sino de simbolización cultural kamëntsá. Son tres los colores tradicionales que se encuentran en la faja: el verde, que alude a la vegetación y se elabora gracias al Kikuyo; el sol y su vitalidad se encuentran en el rojo, obtenido de la mora silvestre; y el blanco de la lana sugiere la grandeza del alba, la renovación de los ciclos y el inicio de la visión. 
Al hablar de las fajas, doña Pastora mencionaba que, además de los colores tradicionales, hay otros que se emplean para tejer con la finalidad de distinguir ENTRE lo masculino y lo femenino, porque en ambos la naturaleza se expresa de forma distinta ${ }^{8}$. La elección de los tonos dependería de la experticia de la artesana, de su conocimiento y de las necesidades particulares del tejido, pues esta práctica puede estar encaminada a un propósito específico, como influir en un eventual proceso de sanación: "[...] uno puede elegir porque cuando uno teje tiene visiones sobre los colores que le sirven a uno para sanar entonces, tejer sana hace que uno elija mejor lo que le conviene" (Comunicación personal, marzo 3, 2014). Por otro lado, la batá María Luisa explica que, en determinados momentos de la vida, los colores de la faja son espejos de nosotros mismos, porque durante la adolescencia somos diferentes a como somos en la madurez: "una jovencita usará una faja rosada con verde azulado porque es alegre, como esos colores, es festiva. El rojo es muy serio. Es para nosotras, los que ya somos mayores" (Comunicación personal, junio 24 de 2014).

En el proceso del tejido la lana deviene en pensamiento y genera reflexión. Doña Margarita Chindoy, quien vive en la vereda de la Primavera, es reconocida entre la comunidad Chindoy por dedicarse a urdir, cocinar y vivir del mismo modo en que lo hacian los abuelos. Cuando urde, para sentirse cerca de Tsbatsam Mamá, lo hace en el espacio del fogón, visto por el kamëntsa como generador de vida e integridad, cerca de los alimentos que recolecta (por lo general choclo, frijol y panela). En su caso, este espacio se encuentra próximo al lugar de los animales representativos de la chagra -cuyes, conejos y algunos pollos-. Aquí, doña Margarita clava en el suelo de tierra pisada seis palos lisos de manera vertical, ubica el banquito para meditar en frente de los palos y empieza a cruzar las lanas, el pensamiento, el recuerdo y el sentimiento que dotarán de vida al tsombiach (Diario

Esta declaración se integra al sentido de polaridad manifiesto no solo en las artesanías andinas, sino en la concepción de otorgarle sexualidad a las cosas del mundo. "Acorde con la génesis mítica y de filiación sexual de los seres y elementos, los andinos entienden la dualidad como: hombre-mujer; sol-luna; sierra-mar; frío-calor. Desde esta matriz cósmica concibieron al mundo como capas que se extendian latitudinalmente, aunque en niveles, de ahí proviene el concepto de bipartición que luego se trasmitiria a muchos binomios posibles" (Paz, 2007, p. 47). No obstante, conviene evitar encajar a la mujer en una imagen basada en asociaciones que parecen evidentes pero que se enlazan de manera problemática. Judith Butler afirma que es preciso evitar fijar al género como una forma de identidad, pues este es mutable, no contextual. 
de campo, marzo 22 de 2014). Al urdir, doña Margarita se percata de cruzar las lanas por los palos que corresponden para formar las partes que conforman la faja. En el fondo, en la parte central, se teje la trama blanca de la urdimbre que sirve de base para la labor, regularmente roja, donde se plasman las figuras que animan las historias del tsombiach. Por último, el filo, usualmente verde, se extiende a los dos lados de la faja en sentido horizontal. En esas historias del tejido, más allá de su valor hereditario, se cifra la experiencia de la vida materializada en la práctica de tejer y la manera personal en la que a cada batá se le revela un camino de conocimiento.

\section{La narración y la palabra}

Vehículo de mensajes, fuerza interior y descubrimiento del ser femenino, el tejido se manifiesta como un texto que, en muchos casos, se expresa como relato oral, oración o invocación, ya sea a la virgen María, ya a las fuerzas de la naturaleza o a los consejos de los abuelos.

Entre invocaciones ${ }^{9}$ y tejido, el hilo es guiado por las manos de la batá, quien narra los encuentros y desencuentros del pueblo kamëntsá; con sus manos integra, con su voz otorga el poder de las palabras que "entrañan un potencial mágico, $[\ldots]$ vinculado, al menos de manera inconsciente, con su sentido de la palabra como por necesidad, hablada, fonada y, por lo tanto accionada por un poder" (Ong, 1987, p. 39). El discurso canónico y hegemónico ${ }^{10}$ de la literatura es puesto a prueba por la capacidad sintética y expresiva del tsombiach. Luz María

9 Doña Margarita decía que oraba para que nadie le hiciera daño y el mal que le deseaban nunca la tocara (Diario de campo, marzo 23, 2014). La oración es tan intensa como el tejido. Elyzabeth Wayland comenta: "cloth and clothing often invoke magic in their encoding. Within this magical world, fertility, prosperity and protection are three of the most common objectives" (1994, p. 155). La protección, en relación con el tejido y la oración, señala que el deseo personal se confunde con el quehacer personal y que el código de creación puede ser invocativo, pues "cloth can be used to invoke magic, even to curse" (Wayland, 1994). El refuerzo de lo intimo, como las actividades de rezar y tejer, subyace a "un evento más complicado que implica la predicción y augurio de sucesos buenos o malos mediante el extraño acontecimiento llamado suerte, y a veces magia" (Paz, 2007, p. 52).

${ }^{10}$ Bill Ashcroft afirma que la lengua se sostiene como una "representación monocrítica" (1998, p.29) donde el poder actúa como una línea de conflicto. Es decir, "la lengua es un medio para mantener una estructura jerarquizada y establecer conceptos de verdad, orden y realidad" (Aschcroft, Griffiths, \& Tiffins, 2002, p. 183). 
Lepe propone que "el estatuto de lo llamado literario puede plantearse no solamente a través de la escritura, sino también de lo marginal no escrito" ${ }^{11}$ (2005, p. 28). El tsombiach, con su doble discurso -tejido y oral-, da cuenta de la necesidad de una noción elástica de la literatura, que va más allá de la letra y de lo oficial ${ }^{12}$. Mixto en su materialidad y en sus procesos de evocación y significación, la faja adquiere significado y niveles discursivos por medio de herramientas válidas pero no convencionales. Desde aquí surge un puente de observación,donde el "hecho literario" (Culler, 2007) recodifica sus limites. Gordon Brotherson ha señalado que la división occidental entre la escritura y la oralidad no es adecuada para concebir "riqueza de los medios literarios de la América Indígena" (1997, p. 24). Por ende, un análisis de las formas textuales y orales de la faja requiere de la negociación de saberes, desde las categorizaciones de la oralitura (Fall, 1992; Friedemann, 1999), las literaturas indígenas (Vásquez, 1999) o la etnoliteratura (Niño, 1996) ${ }^{13}$.

Al igual que en el tsombiach, en este tipo de expresiones se reconoce lo extra verbal como parte de una narrativa híbrida, un estilo que depende de una selección de elementos que busca, en su composición, un desempeño creativo, pautado por determinadas reglas estéticas que se transmiten por legado familiar o por una intención comunicativa específica, como es el caso de las historias personales. Así, la faja kamëntsá se perfila dentro del ámbito literario con una serie de rasgos que caracterizan su pragmatismo y consolidan su eficacia simbólica como una totalidad. El tejido aborda las manifestaciones vitales de la comunidad. Pablo Jamioy, hijo de la batá Georgina, relata cómo la metáfora del tejido proyecta identidad:

El tejido es un aspecto de la vida kamentsá. Nunca es el tejido por sí mismo, de él van de la mano formas de gobierno, regulaciones ambientales, la educación, la historia [...] Para entender el tejido hay

${ }^{11}$ La aparente oposición entre las distinciones de lo oral y lo escrito puede ser considerada más como variaciones del formato (Blanche-Beneviste, 1993, pp. 8-9).

${ }^{12}$ Hugo Niño nos recuerda que el orden historiográfico es de orden literario (1996, p. 111).

${ }^{13}$ Los cuales son "nuevos significantes alternativos para denominar a un tipo de texto cuya filiación es generalmente oral, cuyos territorios de origen y circulación primaria responden a la baja cultura, según el canon, cuyas lenguas de expresión no son las de la literatura universal" (Niño, 1996, p. 20). 
que comprender la forma de ser kamëntsá. El tejido es muy íntimo porque es un reflejo de la vida social, hay que latir con él, porque va unido al corazón, y antes que pensar hay que sentir, latir. Las batás son muy reservadas con ese conocimiento, sobre todo porque si todo el mundo sabe qué es lo que somos, entonces ya no lo somos más, perdemos nuestra identidad, nuestro secreto. (Comunicación personal, marzo 22, 2014)

El tsombiach almacena los elementos que abastecen a la cultura kamëntsá de memoria, trasmite de forma creativa los valores sociales, "abre un espacio al individuo al visibilizar un arte propio en una tradición colectiva" (Aguilera, 2014, p. 197). La leyenda de Juanito el Oso, relato tradicional del tsombiach, relatado acá por doña Georgina, es un ejemplo de lo anterior:

Juanito el oso raptó a Bembe cuando ella cuidaba sola la chagra, los padres de la niña estaban de fiesta. Cuando la niña iba a revisar la talanquera el oso la agarró, se la llevó para una cueva que tapó con una roca grande. Ella lloró noche y día, el oso enloquecido le daba de comer carne cruda pero ella no comía. Estuvo muy triste pero al final se volvieron amigos, ella tuvo un hijo de él, mitad humano, mitad bestia; se llamó Juanito el Oso, y quería mucho a su mamá, porque se daba cuenta de su llanto frecuente. Juanito ayudó a huir a Bembe, corrió la piedra que bloqueaba la cueva mientras el oso cazaba. Juanito cargó a su mamita en el lomo y corrió por todo el bosque, su padre lo persiguió pero ellos llegaron al pueblo y advirtieron a la gente que venía el Oso a atacarlos. Pusieron un tsombiach en la entrada del pueblo, lo movieron como serpiente, engañaron al oso y lo mataron. Juanito y Bembe vivieron en la casa de los padres de ella, que ya habían muerto. Juanito sufrió mucho, no lo querían pero fue noble, valiente y murió en la guerra con los primeros blancos. (Comunicación personal, junio 6, 2014)

Para las batás, la historia de Juanito"14 es "historia antigua", pues se remonta a los tiempos en que los hombres y los animales practicaban una comunicación espontánea y natural. Incluso cuentan que

\footnotetext{
${ }^{14}$ Relato tradicional del tsombiach, recogido aquí de cuatro batás entrevistadas, de familias distintas.
} 
"el oso antes de secuestrar a Bembe tomó la corona emplumada del padre de la niña y se puso a bailar como taita, era un chamán”. (Doña Dolores, Comunicación personal, junio 22, 2014)

Las tejedoras utilizan su conocimiento y sensibilidad para urdir prendas que satisfagan sus necesidades personales, sociales y ambientales. El tsombiach es el resultado de estos factores, de un proceso de interacción y producción de los conocimientos prácticos que se corresponden con el entorno, dotando al mundo social de múltiples significados. Por tanto, las historias del tsombiach son inteligibles según la función contextual y significativa para la comunidad. Esta característica tranza la principal diferencia con el texto letrado, pues el dinamismo de la faja, su potencial de creación y recreación, como anota el semiólogo Enrique Ballón, oscila entre lo estético y lo estésico, es decir, entre los rasgos de:

[...] profundidad, belleza, buen gusto y preciosidad, y al mismo tiempo entre su perennidad, su objetivo civilizador, práctico o de cohesión del grupo por afianzamiento de la memoria colectiva, la estabilidad estructural y la capacidad de satisfacer el horizonte de espera sensible, emotiva ${ }^{15}$. (Ballón en Toro, 2011, p. 262)

El estudio de la faja, en su alternancia entre escritura y oralidad, ya sea desde la traducción en el diálogo cultural -etnotexto-, desde el reconocimiento oral y estético de las tradiciones literarias ancestrales -oralitura- o incluso desde su escritura autóctona -literaturas indigenas-, contribuye a la apertura del diálogo como una forma más de heteroglosia ${ }^{16}$. Ballón afirma que el reconocimiento de lo literario en lo oral ocurre desde "la organización discursiva y narrativa del relato" (Ballón en Toro, 2011, p. 242). Niño, por su parte, proclama que este ocurre desde la etnoliteratura, donde el impacto del mito

15 La cualidad de lo estésico también atañe a lo que Jodelet denomina las "modalidades de pensamiento práctico orientadas a la comunicación, la comprensión y el dominio del entorno social y material" (Jodelet, 1991 en Lepe, 2006, p. 33).

${ }^{16}$ La heteroglosia "es un sistema literario caracterizado por el multilingüismo y la pluriculturalidad, lo cual se relaciona con el concepto de espesor planteado por Ángel Rama, quien vislumbra la literatura a través de la interrelación y convergencia de diversas expresiones literarias" (Toro, 2011, p. 242). 
en la narratología logra un reconocimiento de la producción oral del relato narrado.

Desde las características propuestas por Ballón, lo literario se presenta gracias al acople de:

[...] un conjunto de funciones y motivos, entendiendo los moti$\operatorname{vos}^{17}$ como unidades temáticas que representan lo más pequeño del relato oral, y al mismo tiempo por los motifemas, que son la realización del motivo [...]. El análisis de los componentes estéticos de las tradiciones orales se aprecia como el estudio de las unidades temáticas de las mismas. (Ballón en Toro, 2011)

Aquí, la producción de narraciones en el tsombiach precisa de una comprensión holística, pues sus formas revelan interpretaciones didácticas de la naturaleza en su diálogo con el hombre:

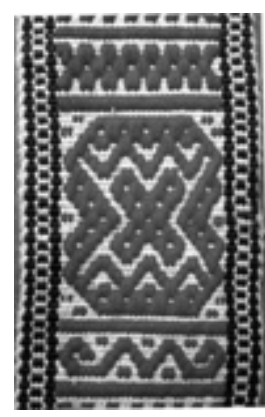

Figura 2. Representación gráfica de la leyenda del conejo en la chagra

Fuente: fotografia de un tsombiach urdido por doña Margarita Chindoy realizada por la autora.

Un anciano tenía chagra. Le gustaba sembrar y se daba cuenta de qué bonita estaba la frijolera. Cuando de un momento al

${ }^{17}$ Los motivos se definen como "unidades móviles que tienen la propiedad de emigrar entre diferentes tipos de relatos en un universo cultural determinado e incluso fuera de los límites de un área cultural precisa" (Ballón en Toro, 2011, p. 242). En consonancia con Ballón, Michéle Ballez explica que "los cuentos de tradición oral son un paradigma de comunicación local y global porque el proceso de globalización es lento, libremente consentido y, de hecho inconsciente. La ausencia de propiedad intelectual, de publicación, es decir de forma de comercio, hace posible una globalización acertada, respetuosa de cada pueblo, de cada idioma" (2006, p. 16). 
otro fue a ver y la chagra estaba trochada. Entonces, el anciano se preguntó: ¿pero qué animal estará haciendo daño?, yo voy a ir a espiar qué será. Cuando se fue a ver, encontró un nido de abejorro y miel en una cera. Entonces esa cera [que] había encontrado [era] grande, le gustó y la guardó. Se fue pues a espiar; había puesto esa cera, para matar al animal, cogió un machete, le dio forma a la cera, hizo la carota, las orejas con esa cera de abejas, que si lo picaran, lo dejarian bien gordo. Colocó la cera en la talanquera e hizo la figura de un muñeco ${ }^{18}$ por todo el camino que fuera a pasar el conejo. Entonces, venía ese conejo: brinque y brinque, y dizque le dijo primero: —iQuítate de aquí! [le dijo el conejo a la figura de cera], no le había contestado. Quítese de aquí. Tampoco. ¡Deme permiso que tengo que pasar! Nada, no le contestaba. -Bueno [dijo el conejo], le voy a echar patada. Le echó la patada se le pegó. Le voy a echar manga y le pegó con la mano y se le pegó, con la mano izquierda y se le pegó, que le voy a dar otra patada, se le pegó. Quedaron todos los cuatro brazos tendido con el muñeco. Entonces gritó. Salió el anciano, y claro, preciso ahí el pobre conejo. De ahí dicen que lo había soltado, pero que quiso como cogerle la cola y la cola se le había arrancado que por eso es pucho. (Doña Margarita Chindoy, Comunicación personal, junio 12, 2014)

El deseo de relatar toma su cauce a partir de una escucha aguda. Las personas y los seres se funden en el relato para explicar ciertas formas de personalidad, carácter y afinidad en la naturaleza.

\section{La experiencia personal como historia de transformación}

Las batás no solo atesoran la tradición en el tsombiach, sino que confían en él su vida personal. El calor de cada vientre de mujer pone en

${ }^{18} \mathrm{El}$ muñeco simbólico o humunculus (hombrecillo pequeño) está relacionado con los símbolos del duende y el enano. En los cuentos de hadas se manifiesta con un halo de sabiduría, posee la capacidad de transformar. En este caso el muñeco de cera sugiere el respeto de los límites que el conejo transgrede. El muñeco es una manifestación idealizada de lo que debería ser el conejo, por esta razón el conejo real queda pegado en la superficie de la cera, sin darse cuenta que era una trampa. En sí la figura de cera es una figura moralizante. 
marcha un universo de aprendizaje. Dice doña Georgina Juagibioy: "El tejido es vital, da concentración, memoria. La urdimbre da instinto para conocer a profundidad" (Comunicación personal, marzo 24, 2014). Su forma de aprender del tsombiach es parte de la efectividad narrativa y evocativa que posee la faja. El tsombiach escucha, interpela, se explica y va cifrándose con quien lo porta. Las historias y las palabras nos remiten al acto de creación. Doña Margarita Chindoy relata cómo la experiencia de contar cuentos y de tejer dota a la vida de un sentido especial, puesto que le infunde "un don" de reciprocidad y gratitud, traducido en las historias de la experiencia personal.

Mi Dios me ha tenido unas ciertas esperanzas desde niña. He tenido que conocer mucho en la vida. Buenos resultados, amargos; de todo un poco. Gracias a Dios, hasta esta fecha me alegro con el sufrimiento y con la vida que mi Dios me dio. (Comunicación personal, junio 12, 2014)

En otro momento, la batá recalca que cada experiencia de aprendizaje es tomada por ella como alimento, un grano de maíz que crece para ser otorgado al porvenir y al servicio de seres que no sabrán de nosotros sino "de la vida que nosotros mismos nos arrancamos de la boca como si fuera pan" (Dolores Butumabajoy, Comunicación personal, junio 25, 2014). Vivir y contar la vida son maneras de hacerse responsable del otro.

Nuestras lágrimas y risa son maíz. El maíz es un grano muy respetable, no se puede tratar mal porque esos tienen su dueño, igual que uno, me acuerdo de cuando me trataron mal, de cuando estuve triste. El maíz que está mezclado con la basura no deja de ser amarillo, eso me da contento, fuerzas, porque así mismito uno no deja de brillar cuando está solo. (Doña Margarita, Comunicación personal, junio 12, 2014)

El taita Alberto Juagibioy explica que, al ser un grano sagrado, el maíz debe ser custodiado con respeto, ya que él representa "la vista de Dios" (Fajardo, 2006, p. 403). Esa misma propiedad nutritiva y benéfica del choclo es aprehendida en el tejido para narrar historias, 
porque los cuentos, según doña Beatriz Otaya, son como medicinas, nos explican de qué nos tenemos que purgar.

Por su lado, batá María Luisa nos señaló una de las figuras de la faja en las que ella más se inspira para trabajar espiritualmente, se trata de "la unión de la familia". En este pictograma, la unión del monte y de lo desconocido va acortando distancia en torno al tallo del maíz. Los granos de la mazorca, puestos de forma cardinal, encarnan la bonanza de un camino bendecido.

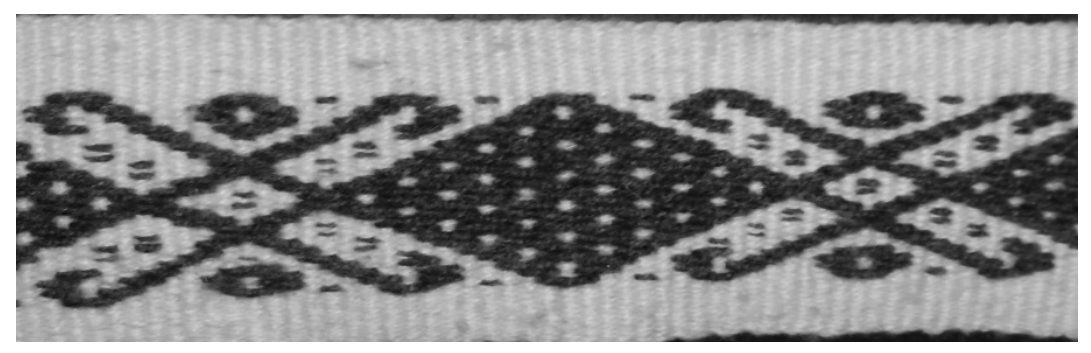

Figura 3. Maíz en un tsombiach de lana virgen sin teñir

Fuente: Fotografia de un tsombiach urdido por doña Maria Luisa Jasansoy tomada por la autora.

El tsombiach es entonces un producto que dialoga y negocia con el relato popular, la historia y las historias familiares, y con la dinámica de interpelación de la oralidad y de la escritura autóctona. Más allá de la transmisión de los mensajes que abordan las fajas, es posible también entender su urdido como una forma de vencer la soledad, de situarse en la compañia de quienes ya no están y de aceptar o limitar la tradición religiosa, permitiendo leer en código las historias de la cristiandad, junto a las historias de la naturaleza y el folklore. De acuerdo con doña Margarita, el tsombiach es la forma de "convivir con los abuelos" (Diario de campo, marzo 22, 2014) y, según doña Georgina, "es una manera de vivir, de leer y de trabajar. El vientre es el que recuerda las historias, el que cocina la vida, es el fogón. Uno va contando lo que le pasa, lo que siente mientras está cerca al fuego. En el vientre y en el fogón surge la historia" (Diario de campo, marzo $24,2014)$. 
El tsombiach posee "una estilistica que pasa por lo verbal, pero que se configura realmente en su performancia y en su capacidad de procesar conceptos" (Niño, 1998b, pp. 113-114). En esta cinética adquiere poder; la facultad de "movernos desde adentro y cambiar o restablecer el modo en que vemos y sentimos las cosas colectivamente" (Rocha, 2006, p. 33). Las batás fecundan la palabra en el tejido, pues la "palabra del hacedor está cargada de magia, constituyen y dan vida a seres y a cosas" (Lepe, 2005, p. 102). Este dar vida es una conciencia especial del ser mujer y ser madre como acto creador, porque:

Lo femenino y la creación artística que el tejido propone y dispone como reiteración de lo mismo, [se] convierten en diferencia [con] cada puntada. Ese hacer diverso que mantiene vivo el tejido en la historia humana propone la diversidad y la irrepetible identidad del diseño como condición de estilo. (López, 1994, p. 100)

La capacidad de mediar entre la singularidad de cada acontecimiento -verbal y textual- por medio del urdido propone hacerse de los tiempos míticos, uterinos e históricos en los cuales las bts mamá ${ }^{19}$ se relacionan con el discurso total de su grupo y de la historia para aceptar o negar el discurso y acoplarlo a su experiencia. En las artesanas reside la eficacia simbólica del discurso, pues al ser sujetos de enunciación, esperan respuestas y actos que tienen como fin entablar un diálogo para la comunidad ${ }^{20}$. Por este motivo las historias o 'relatos físicos' se configuran como un acto de poder, como un recurso que se centra en la experiencia de la naturaleza, de sus contenidos y de una transformación vital y narrativa de los individuos de una manera consciente. Esa cualidad de 'ser consciente en todo lo que se realiza' faculta a las tejedoras para organizar el pensamiento desde el oficio. Doña Margarita Chindoy, al igual que doña Pastora Juagibioy, relata la concentración y la entrega en la que el tejido sitúa la mente y los pensamientos, el momento de la definición de los instantes y la ora-

19 Abuela en lengua kamëntsá.

${ }^{20}$ La magia social ocurre cuando se establece la relación entre las propiedades del discurso, las propiedades de quien lo pronuncia y las propiedades de la institución que autoriza pronunciarlo (Bourdieu, 2008, p. 84). 
ción que, como las hebras, van juntándose para significar y poder ser leídas por la naturaleza y por $\operatorname{Dios}^{21}$.

\section{Conclusiones}

El tsombiach posee cualidades de corte estético y estésico y funciona como un recurso cohesionador de la comunidad kamëntsá. Se presenta como un hacer ancestral llevado a cabo por mujeres que, a partir de él, no solo crean artesanalmente, sino que logran desatar todo un sistema de producción de sentidos y, a la vez, un lugar integrador del conocimiento. El tsombiach asume las características de una poética al regir el destino por medio del arte narrativo. En la cristalización del signo/palabra y símbolo del tsombiach, es posible reconocer en él una ruta del lenguaje y, al mismo tiempo, un sistema de pensamiento e interpretación del mundo que más que oponerse a los valores normalizadores de occidente, los acopla y resignifica. Dentro de este esquema de pensamiento, el significado de la realidad se constela de sentido gracias a la elaboración de objetos que permiten la multireferencialidad de prácticas que son afines para entender la realidad desde categorías vitales que permiten desentrañar la conceptualización del universo para explicar toda una cosmovisión y para darle vigor a una cultura ancestral que, por medio del ejercicio de la urdimbre, se fortalece y reactualiza.

${ }^{21} \mathrm{Al}$ preguntarle a las batás por su relación con el tejido, tanto doña Margarita como doña Pastora aludieron al hecho de que el urdido no es para perezosos. Para tejer hay que tener la cabeza bien plantada, vencer al sueño, dormir poco para ver más. Rezar por la madrugada para conocer y ayudar incluso a quienes no nos son familiares. El destino de urdir y de ser artesano está signado de forma divina, es un proceso de transición. comenta doña Pastora Jamioy que su primera ceremonia fue una iniciación religiosa en la que "los ángeles me cantaban al pie de escaleras que ascendian entre nubes y estaban tejidas, fui feliz y canté. El taita me dijo que yo era una hija especial de mi Dios". Por su cuenta doña Margarita confiesa que desde niña le enseñaron a tejer y a urdir. Lo hacía imitando a su madre que le enseñó con amor. Un día un cinturón que estaba haciendo fue quemado por su padre porque según éste "esa niña es una inútil, perezosa, no teje como mujer". Doña Margarita se puso muy triste y desconsolada, fue a aliviar sus penas con la madre, quien viendo el tejido de Margarita le dijo que estaba muy bien. Que lo que había hecho su padre era solo una manera de ponerla a prueba y volverla siempre mejor, porque a las verdaderas artesanas siempre se les presentaban pruebas que endurecian su carácter y mejoraban su técnica (diario de campo, 03/21-25/14). 


\section{Referencias}

Aguilera, S. (2014). Textiles Ralámuli, Hilos, caminos y el tejido en la vida. Berlín: Ibero-Amerikanisches Institut, Preußischer Kulturbesitz. Gebrüder Mann Verlag.

Aschcroft, B., Griffiths, G. y Tiffin, H. (2002). The empire writes back: theory and practice in post-colonial literatures. Estados Unidos: Routledge.

Ballez, M. (2006). Las tradiciones orales: ¿paradigmas de la comunicación local y global? En Granda Paz, O., y Lepe Lira, L. M. (Coords.). Comunicación desde la periferia: Tradiciones orales frente a la globalización (pp.11-18). España: Antrophos.

Ballón, E. (2006). Tradición oral peruana: literaturas ancestrales y populares. Vol I. Perú: Pontificia Universidad Católica del Perú.

Blanche-Beneviste, C. (1993). Estudios lingüisticos sobre la relación entre oralidad y escritura. España: Akal.

Bourdieu, P. (2008). ¿Qué significa hablar? Economía de los intercambios lingüísticos. Madrid: España. Akal.

Brotherson, G. (1997). La América indigena en su literatura los libros del cuarto mundo. México: Fondo de Cultura Económica.

Chacón, M. (2007). Poetizas mayas. Subjetividades contra la corriente. Cuadernos de literatura, 11(22) 99-106.

Culler, J. (2007). The literary in theory. California: Stanford University Press.

Davis, W. (2001). El río. Exploraciones y descubrimientos en la selva amazónica. Bogotá: Banco de la República, El Áncora editores.

Derrida, J. (2010). De la gramatología. Madrid: Siglo veintiuno editores. 
Fajardo, J. (2006). El Carnaval del Perdón. Revista Porik An, 400-416. Recuperado de http://www.unicauca.edu.co/porik_an/imagenes_3noanteriores/ No.11 porikan/articulo12.pdf

Fall, Y. (1992). Historiografia, sociedades y conciencia histórica en África. En África, inventando el futuro (pp. 17-37). México: Centro de estudios de Asia y África, El colegio de México.

Friedemann, N. (1999). De la tradición oral a la etnoliteratura. Oralidad, 10, 19-27.

Granda, O. (2007). Hacia una semiótica del textil artesanal. Barranquilla: Editorial Travesías.

Lepe, L. M. (2005). Cantos de mujeres en el Amazonas. Colombia: Convenio Andrés Bello.

Lepe, L. M. (2006). Representación social y mecanismos de la tradición oral en tiempos de globalización. Mujer mono: canto local y global. En Granda Paz, O. y Lepe Lira, L. M. (Coords.). Comunicación desde la periferia: Tradiciones orales frente a la globalización (pp. 31-40). España: Antrophos.

López, M. (1994). El tejido como escritura y el orden femenino. Manos que no descansan. Historia Crítica, (9), 95-101.

Muchavisoy, N. I. (2003). Fortaleciendo la educación Indigena Kamëntsá a través del Tsombiach. Tesis de pregrado inédita. Universidad de los Andes. Bogotá, Colombia.

Niño, H. (1996.) Otra vez la doble historia de las epopeyas míticas amazónicas. Casa de las Américas, 37(204), 111-117.

Niño, H. (1998a). El etnotexto voz y actuación en la oralidad. Revista de Crítica Literaria Latinoamericana, 24(47), 109-122.

Niño, H. (1998b). Poética indígena, diáspora y retorno. Revista Cuadernos de Literatura, 4(7-8), 216-228. 
Niño, H. (1998c). Escritura contra oralidad: ¿y dónde está el documento? Casa de las Américas, 39(213), 79-86.

Ong, W. (1987). Oralidad y escritura, tecnologías de la palabra. México: Fondo de Cultura Económica.

Pinzón, C. y Garay, G. (1998). Inga y Kamëntsá. En Corea Rubio, F. (Coord.). Geografia Humana de Colombia. Región Andina Central, tomo IV, volumen I (p. 250). Colombia: Instituto Colombiano de Cultura Hispánica.

Ramírez, M. (1996). Frontera fluida entre Andes, piedemonte y selva el caso del Valle de Sibundoy, siglos XVI-XVIII. Colombia: Instituto Colombiano de Cultura Hispánica.

Reynoso, (1987). Paradigmas y estrategias en antropología simbólica, colección de estudios antropológicos, Buenos Aires: Ediciones Búsqueda.

Rocha, M. (2006). Antes el amanecer: antología de las literaturas indigenas de los Andes y la Sierra Nevada de Santa Marta. Colombia: Ministerio de Cultura.

Severi, C. (2012). The arts of memory, comparative perspectives of a mental artifact. Hau: Journal of Ethnograhic theory, 2(2), 451-485.

Toro, D. (2011). Oralitura y tradición oral, una propuesta de las formas artísticas orales. Lingüistica y Literatura, 65, 239-256.

Toro, D. (2012). Estética de la palabra viva. Las tradiciones orales como creaciones literarias. Boletín de Antropología, 26(43), 260-262.

Vásquez, J. (1999). Literaturas indigenas de América: Introducción a su estudio. Barcelona: Azul editorial.

Wayland, E. (1994). Women's work: the first 20,000 years: women, cloth, and society in early times. Nueva York: W.W. Norton \& Company. 
Cómo citar este artículo

Leyva-Mosquera, S. D. (2016). El tsombiach: tejiendo la vida entre memoria y tradición. Universitas Humanística, 81, 229-253. http:/ /dx.doi.org/10.11144/ Javeriana.uh81.ettv 